\title{
O sublime e a coragem possível: uma contribuição do Grande Sertão: Veredas para a Literatura Brasileira
}

\section{The sublime and the possible bravery: a contribution of The Devil to Pay in the Backlands to Brazilian Literature}

\author{
Renato Rocha de Oliveira \\ Universidade Federal de Minas Gerais (UFMG), Belo Horizonte, Minas Gerais / Brasil \\ renato.nitu@gmail.com \\ Elcio Loureiro Cornelsen \\ Universidade Federal de Minas Gerais (UFMG), Belo Horizonte, Minas Gerais / Brasil \\ emcor@uol.com.br
}

Resumo: Este artigo aborda a influência de Diadorim sobre Riobaldo em Grande Sertão: Veredas, pela perspectiva filosófica do sublime e da coragem (Schiller e outros), baseando-se em concepções de Walter Benjamin e dialogando com a crítica de Willi Bolle. O ensaio identifica, na obra-prima de Guimarães Rosa, uma relação importante entre o sublime, associado a Diadorim a partir de elementos levantados por Benjamin, como a figura guia, o amor provençal e o justo hermafrodita, e a coragem demonstrada por Riobaldo. Finalmente, contribui para a avaliação de Bolle quanto ao caráter dialético e verossímil do texto literário no que concerne à coragem desse personagem, em comparação com a representação do sertanejo em Os Sertões, de Euclides da Cunha.

Palavras-chave: Diadorim, figura guia, sublime, coragem, Benjamin, Bolle.

Abstract: This article approaches the influence of Diadorim upon Riobaldo in The devil to pay in the backlands through the philosofical perspective of sublime and courage (Schiller and others), based on Walter Benjamin's conceptions and in dialogue with Willi Bolle's critique. The essay identifies, in Guimarães Rosa's masterpiece, an important relation between the sublime, associated with Diadorim per elements raised by Benjamin, as the guide figure, the corteous love, the hermaphrodite just, and the bravery showed by Riobaldo. Finally, contributes to Bolle's evaluation of the dialectical 
and verisimilar character of the literary text concerning this character's courage, in comparison with the countryside representation in The Backlands, by Euclides da Cunha. Keywords: Diadorim, guide figure, sublime, courage, Benjamin, Bolle.

\section{Introdução}

De acordo com Willi Bolle, a figura de Diadorim exerce uma influência mais elevada e transformadora no leitor de Grande Sertão: Veredas do que aquela da rotina da jagunçagem. Diadorim, para ele, assim como para outros autores, constitui o cerne e o centro emocional da obra. $\mathrm{O}$ autor fala de vários enfoques com que Diadorim tem sido avaliado pela fortuna crítica: 1. Filosófico-cultural em direção ao amor; 2. encarnação do topos literário da donzela-guerreira; 3 . Figura andrógina e iniciática; 4. Figura da poética de Guimarães Rosa. Bolle adota a quarta abordagem em seu grandesertão.br, considerando que Diadorim é o princípio organizador de toda a obra, e, assim como a Beatriz de Dante, é uma figura que funciona como guia, perspectiva de salvação e revelação. Esse estudo opta por percorrer, com base na categoria estética do sublime, e emprestando concepções de Walter Benjamin, essa mesma perspectiva, mas também a primeira e a terceira. A segunda nos parece óbvia e menos interessante.

Vejamos a abordagem de Bolle:

O conceito guia desta interpretação é a paixão estética, que permite abranger os vários planos do romance, inclusive a filosofia da história do autor. Esse conceito é usado por Walter Benjamin (apud BOLLE, 2004), interlocutor de Auerbach, no seu projeto das Passagens parisienses como uma categoria construtiva para organizar a experiência do indivíduo no espaço histórico-cultural da Modernidade. Entendo a paixão como a forma mais densa de organização do tempo, do saber e da energia, na dimensão de uma vida humana, como também de uma geração ou de um período histórico. (BOLLE, 2004, p. 197)

O estudioso afirma que Diadorim é o princípio inspirador pelo qual Rosa estrutura a grande quantidade de elementos do sertão em sua obra, e que corresponde à paixão estética do autor em sua escrita. Entendemos, assim, que a paixão de Riobaldo, como circunstância fundamental de sua subjetividade, justifica a densidade, a intensidade e a sublimidade de sua narração. 
Façamos um pequeno panorama sobre conceitos do sublime que usaremos. O objeto sublime, segundo Burke (1993, p. 56, 59), gera um deleite, um prazer negativo, pois é algo poderoso e terrível que poderia causar a morte ou a dor. Assim, para experimentá-lo, é preciso estar resguardado de sua ameaça. De acordo com Burke (1993, p.65), o sublime envolve uma simpatia pela qual é possível ao indivíduo livrarse do constrangimento da realidade e da prisão de sua individualidade, e colocar-se no lugar do outro. Longino (1996, p. 54) afirma que "o sublime é o eco da grandeza de alma", uma força irresistível que não se impõe pela razão, mas pelo êxtase. Figueiredo (2011, p.48) explica que o espectador capaz do sentimento do Sublime diante de uma obra de arte seria aquele que se identifica com ela, e no qual há um desfalecimento entre suas fronteiras e as do objeto. O sublime, para Kant (1993, p.95), seria o movimento da imaginação libertando-se da noção subjetiva de tempo para experimentar sensações inexprimíveis. Finalmente, Schiller considera que o sublime está numa liberdade que envolve o valor da verdade e da eticidade para além da natureza (incluindo interesses e desejos físicos), e a aceitação das imposições desta contra as quais não se pode lutar (SCHILLER, 2016, p. 61-62).

Queremos propor que Diadorim gera em Riobaldo sentimento sublime, que envolve perigo e salvação, horror, admiração e vivacidade, segundo Burke e vários outros filósofos, e que essa sensação coopera com a influência daquele amigo/amante sobre o protagonista no sentido de ter coragem, que, por sua vez, é uma virtude sublime, como afirma Longino (1996, p. 48). Essa categoria estética é a essência da grande arte para Schiller e Hegel (apud FIGUEIREDO, 2011, p. 48) e nos parece ser, na verdade, a essência da paixão estética, cuja importância para o sujeito moderno Benjamin destaca. Schiller indica, implicitamente, que a experiência sublime promove a coragem. Pretendemos apresentar trechos do GSV relacionando-os a alguns apontamentos de Benjamin que sustentem essa abordagem.

Na sequência, e com Bolle, avaliaremos alguns momentos de luta da coragem contra o medo em Riobaldo para esclarecer um pouco como o Grande Sertão: Veredas critica a visão idealizada do sertanejo que aparece em $O s$ Sertões. Isso permitirá propor que, a partir da investigação da coragem em sua obra, Guimarães Rosa assume um papel literário, político e existencial relevante, dentro da concepção daquele ensaísta, ou seja, do romance como medium de reflexão. 


\section{Diadorim, singular musa da coragem}

A presença de Diadorim perturba Riobaldo, porque a atração que sente por ele é proibida pela sociedade e censurada por ele mesmo:

Mas, essa ocasião, ele estava ali, mais vindo, a meia-mão de mim. E eu - mal de não me consentir em nenhum afirmar das docemente coisas que são feias - eu me esquecia de tudo, num espairecer de contentamento, deixava de pensar. Mas sucedia uma duvidação, ranço de desgosto: eu versava aquilo em redondos e quadrados. Só que coração meu podia mais. O corpo não traslada, mas muito sabe, adivinha se não entende. (ROSA, 2015, p. 36)

Riobaldo, entretanto, deixava-se, em alguns momentos, apreciar o seu amor, quando o coração sobressaía. Isso e o esquecer de tudo, contentar-se, deixar de pensare adivinhar são índices que remetem à experiência do sublime, que suspende o sujeito num êxtase e lhe dá uma intuição inexprimível.

"Mas, se você algum dia deixar de vir junto, como juro o seguinte: hei de ter a tristeza mortal..." [...] Tinha tornado a por a mão na minha mão, no começo de falar, e que depois tirou; e se espaçou de mim. Mas nunca eu senti que ele estivesse melhor e perto, pelo quanto da voz, duma voz mesmo repassada. Coração - isto é, estes pormenores todos. Foi um esclaro. O amor, já de si, é algum arrependimento. Abracei Diadorim, como as asas de todos os pássaros. Pelo nome de seu pai, Joca Ramiro, eu agora matava e morria, se bem. (ROSA, 2015, p. 45)

Esse trecho mostra o matiz sublime do amor entre os dois jagunços, quando a perda do amor, de um lado, ou a defesa do amor, de outro, são associados à morte. $\mathrm{O}$ abraço às asas de todos os pássaros simboliza $\mathrm{O}$ sentimento ou desejo de fusão entre eles, confirmando ou intensificando o sentimento de proximidade mencionado, e uma ideia de sagrada liberdade.

Acreditamos que Diadorim exerce uma função iniciática para Riobaldo. Pensamos ser possível uma aproximação dela com os justos que Benjamin vê nos contos de fada de Leskov. Benjamin destaca, entre esses justos, o hermafrodita Pisonski: 
Durante doze anos, a mãe o educou como menina. Seu lado masculino e o feminino amadurecem simultaneamente e seu hermafroditismo transforma-se em "símbolo do Homem-Deus". Leskov vê nesse símbolo o ponto mais alto da criatura e ao mesmo tempo uma ponte entre o mundo terreno e o supraterreno. Porque essas poderosas figuras masculinas, telúricas e maternais, sempre retomadas pela imaginação de Leskov, foram arrancadas, no apogeu de sua força, à escravidão do instinto sexual. (BENJAMIN, 1994, p. 217)

Se Diadorim não encarna integralmente a sabedoria, a bondade e o consolo do mundo, parece fazê-lo para Riobaldo, na maior parte do tempo. Além de ser sua referência de coragem, trata-o com cuidado e carinho. Diadorim confronta energicamente algumas covardias dos jagunços e do próprio Riobaldo, e tem uma relação terna com os animais e as crianças, como o justo daquele autor. Ora associada à Virgem, ora ao diabo, Diadorim representa, como o hermafrodita referido, a possibilidade de transcendência em direção ao divino, ao sublime. Benjamin ressalta, outrossim, a característica de Pisonski de mover para fora de si, de sua individualidade, que é uma prerrogativa de que quem experimenta tal intensa afecção. Acreditamos que a força de Diadorim está, de alguma forma, associada a sua renúncia sexual em prol do amor a seu pai. Assim diz o seu registro de nascimento, revelado ao final do livro: "De Maria Deodorina da Fé Bettancourt Marins - que nasceu para o dever de guerrear e nunca ter medo, e mais para muito amar, sem gozo de amor..." (ROSA, 2015, p. 489)

Vamos ver alguns exemplos que mostram aspectos importantes da figura de Diadorim para Riobaldo: A intensidade da paixão: "De um aceso, de mim eu sabia: o que compunha minha opinião era que eu, às loucas, gostasse de Diadorim..." (ROSA, 2015, p. 43) O ímpeto do amigo, seu gosto pela guerra e a sabedoria, com interjeições intensificadoras: "Hê, mandacaru! Ôi, Diadorim belo feroz! Ah, ele conhecia os caminhares." (ROSA, 2015, p. 77) A coragem e o prazer em guerrear: "Seja por ser, Riobaldo, que em breve rompemos adiante. Desta vez, a gente tange guerra...'- pronunciou, a prazer, como sempre quando assim, em véspera." (ROSA, 2015, p. 61) A admiração, a alegria e o conforto de sua presença: 
- “Como passou, Riobaldo? Não está contente por me ver?” A boa surpresa, Diadorim vindo feito um milagre alvo. Ao que, pela pancada do meu coração. (ROSA, 2015, p. 200)

Agora eu tinha Diadorim assim perto de afeto, o que ainda valia mais no meio desses perigos de fato. (ROSA, 2015, p. 201)

Nesse trecho temos o índice sobrenatural do milagre, e mais uma vez a menção do coração (a terceira desse ensaio): é desse que Riobaldo tira coragem para permanecer em companhia daquele amigo perturbador, e também para afirmar-se como jagunço. Vale destacar a mesma origem etimológica das duas palavras. Quanto à segunda citação, devemos destacar a relação entre a coragem e o sentimento sublime, sendo um reforçado pelo outro, como podemos entender da teoria de Schiller. Nesse sentido, a presença de Diadorim, que exerce influência sublime em Riobaldo, estimula e aumenta nele a coragem para enfrentar as lutas.

Mais um fator de grandeza em Diadorim pode ser visto aqui: "Como que brilhava ele todo. Porque Joca Ramiro era mesmo assim sobre os homens, ele tinha uma luz, rei da natureza. Que Diadorim fosse o filho, agora de vez me alegrava, me assustava." (ROSA, 2015, p. 46-47) Essas duas impressões do amado sobre Riobaldo são próprias daquelas de um objeto sublime. A figura de Joca Ramiro, pai de Diadorim, é muito exaltada por este e por Riobaldo. $\mathrm{O}$ amor de Diadorim por ele é tão grande que o faz reprimir a sua sexualidade para ser jagunço. De acordo com Wine (1992, p. 16), a sublimação é o caminho da formação do sujeito. Isso confirma os dizeres do registro de Diadorim e a associação com o hermafrodita justo. Além disso, na filosofia de Schiller, a superação dos instintos naturais por valores morais é sublime.

Em certo momento, Riobaldo deixa transparecer a idealização que faz do seu amigo/amante e, na sequência, fala mais uma vez na disposição em morrer:

"Diadorim, meu amor..." Como era que eu podia dizer aquilo? Explico ao senhor: como se drede fosse para eu não ter vergonha maior, o pensamento dele que em mim escorreu figurava diferente, um Diadorim assim meio singular, por fantasma, apartado completo do viver comum, desmisturado de todos, de todas as outras pessoas. [...] Um Diadorim só para mim. [...] Aquela hora, eu pudesse morrer, não me importava. (ROSA, 2015, p. 242) 
Há uma noção fundamental em Benjamin, que aparece no seu ensaio sobre o Surrealismo, que se faz oportuna para avaliar a relação em estudo. "De resto, basta levar a sério o amor para descobrir, também nele, uma 'iluminação profana', como nos mostra Nadja." (BENJAMIN, 1994, p. 24) Ele cita um comentário do autor dessa obra sobre seu interesse pela era de Luís VII, por causa das cortes de amor, e de como ficava fantasiando acerca da vida nesse tempo. Benjamin cita a reflexão de Auerbach sobre o amor daquela época, ao examinar Dante:

"todos os poetas do estilo novo têm amantes místicas. Todos experimentam aventuras de amor muito semelhantes, a todos o Amor concede ou recusa dádivas que mais se assemelham a uma iluminação que a um prazer sensual, e todos pertencem a uma espécie de sociedade secreta, que determina sua vida interna, e talvez também a externa". (AUERBACH apud BENJAMIN, 1994, p. 24-25)

Talvez esse tipo de relação seja útil para esclarecer a "iluminação profana do amor" de Riobaldo e Diadorim, em que o contato corporal é mínimo, mas os gestos são altamente significativos. Segundo Benjamin, o que é sobriedade pudica num mundo pode ser êxtase e transe na castidade do amor cortês. "O amor cortês desemboca num mundo que não confina apenas com as criptas do Sagrado Coração ou com os altares de Maria, mas também com a alvorada antes de uma batalha ou depois de uma vitória." (BENJAMIN, 1994, p. 25) Diadorim e Riobaldo sabem o que é batalha e vitória, e é nesse contexto que se dá o seu amor "mal encoberto em amizade". Ailuminação profana é comparada por Benjamin à iluminação religiosa e é certamente sublime. Vejamos um trecho muito significativo que mostra muito bem a intimidade e a comunicação "telepática" (para usar um termo de Breton) entre Riobaldo e Diadorim.

Sério, quieto, feito ele mesmo, só igual a ele mesmo nesta vida. Tinha notado minha idéia de fugir, tinha me rastreado, me encontrado. Não sorriu, não falou nada. Eu também não falei. [...] Naqueles olhos e tanto de Diadorim, o verde mudava sempre, como a água de todos os rios em seus lugares ensombrados. Aquele verde, arenoso, mas tão moço, tinha muita velhice, muita velhice, querendo me contar coisas que a idéia da gente não dá para se entender - e acho que é por isso que a gente morre. [...] Apanhei foi o silêncio dum sentimento, feito um decreto: - Que você em sua vida toda toda por diante, tem de ficar para mim, Riobaldo, pegado em mim, sempre!... - que era como se Diadorim estivesse 
dizendo. Montamos, viemos voltando. E, digo ao senhor como foi que eu gostava de Diadorim: que foi que, em hora nenhuma, vez nenhuma, eu nunca tive vontade de rir dele. (ROSA, 2015, p. 240)

Mais uma vez, Diadorim aparece como figura singular e até uma espécie de assombração, ou sombra de Riobaldo. Por seus olhos, Diadorim demonstra habitar lugares sombrios dentro de si e do protagonista, e demonstra ser portador de mistérios inexprimíveis, ou seja, é uma personagem eminentemente sublime. A impossibilidade de rir de Diadorim naquele momento, é a mesma de se o fazer diante de um "objeto" terrível, sagrado, inefável.

A moça guerreira é uma recordação de que o protagonista-narrador se apropria para "articular historicamente o passado", como afirmava Benjamin (1994, p. 224): momento delicado e vital que deve ser o mais autêntico. Bolle chama a atenção para o fato de que, diferente da narração de Os Sertões, de Euclides da Cunha, Guimarães Rosa organiza seu relato ao sabor dos sentimentos. Esse autor narra de forma investigativa, tentando entender as emoções envolvidas na relação com Diadorim. Esse é uma figura que representa o caráter labiríntico da história narrada e que, ao mesmo tempo, a unifica e causa-lhe desordem. A obscuridade e o ficar perdido são marcas do sublime para Burke.

Na seção 2 do seu ensaio "Sobre o conceito da História", Benjamin (1994, p. 222-223) avalia que as reflexões sobre a possibilidade de felicidade, bem como sobre o passado, estão ligadas a uma ideia de salvação e de redenção. $\mathrm{O}$ passado transmitiria um apelo à geração presente para algum tipo de ação messiânica. No Grande Sertão, Diadorim se configura como uma formação e caminho para realização de Riobaldo. E a narração das aventuras reflete, também, a busca de sentido para o presente: "Por que foi que eu precisei de encontrar aquele Menino?" (ROSA, 2015, p. 99).

Bolle (2004, p. 205) admite que Diadorim é uma figura iniciática para Riobaldo, quando analisa o primeiro encontro e aventura dos dois, ainda meninos. A travessia do Rio São Francisco condensa o significado de todo o livro. Nela está presente o medo, a perturbação de Riobaldo diante de Diadorim, a atração por ele e a necessidade da coragem. Essa última se torna uma marca de Diadorim para Riobaldo, e durante toda a história aquele vai incentivar a virtude no protagonista, de forma explícita ou indireta. Nesse trecho, vê-se a ligação entre o relacionamento dos dois e a busca de Riobaldo por adaptar-se à vida de jagunço e por coragem: 
Daquilo tudo eu gostei, gostava cada dia mais. Fui aprendendo a achar graça no dessossego. Aprendi a medir a noite em meus dedos. Achei que em qualquer hora eu podia ter coragem. [...] Diadorim e eu, a sombra da gente uma só uma formava. Amizade, na lei dela. (ROSA, 2015, p. 208)

\section{Um herói de carne e osso}

Willi Bolle (2004, p.214) propõe que o Grande Sertão: Veredas pode ser visto como uma crítica a Os Sertões, de Euclides da Cunha. Ambas obras são vistas por aquele autor tanto como discurso diante de um tribunal como discurso fúnebre, que têm o objetivo de fazer um retrato do povo do sertão. Benjamin (apud BOLLE, 2004) usou o conceito de mediumde-reflexão no estudo da crítica poética apresentada pelo Romantismo alemão. Novalis afirmou que "romantizar" seria investigar por meio do gênero literário do romance. Nessa linha, e segundo Bolle, o nosso Grande Sertão critica o discurso euclidiano sobre o Brasil por meio do medium do romance. "Tal trabalho implica também, como esclarece ainda o poeta alemão, uma 'autoperscrutação - o que caracteriza perfeitamente o intenso processo de reflexão posto em obra por Guimarães Rosa com a sua invenção Diadorim.” (BOLLE, 2004, p. 214)

A figura bissexual e ambígua de Diadorim seria o início do rompimento com a visão unilateral de Euclides. Esse retrata o sertanejo como um forte guerreiro e despreza quaisquer outros aspectos desse povo. Rosa responderia a essa visão machista, ainda, ironicamente, pelo amor de dois jagunços. Além disso, o autor configura um mundo inspirado numa mulher e numa paixão estética dotada de sensibilidade masculina e feminina. Outra crítica mediada pelo romance à visão euclidiana consiste em personificar a coragem em Diadorim. Nela a coragem aparece vinculada ao coração e à bondade.

Bolle ressalta ainda a diferença entre a heroização dos sertanejos por Euclides e a luta de Riobaldo contra o medo. Ele menciona o levantamento de Zilly (apud BOLLE, 2004, p.216) dos procedimentos de heroização daquele autor: embora considerado um bárbaro, o sertanejo é "equiparado aos deuses primordiais, [...] aos semideuses, aos heróis da Antiguidade, elevado a 'titã', 'centauro', 'Anteu', [...] a 'Hércules"”. Ele realiza façanhas épicas e é comparado aos guerrilheiros germanos que derrotaram as legiões do romano Varus no ano 9 antes de Cristo. 
Veremos agora como se comporta Riobaldo, e até que ponto desenvolve sua coragem, analisando o episódio final e depois um conflito com Zé Bebelo. Ao contrário dos heróis de Euclides, como Bolle aponta, Riobaldo - o Urutú-Branco - demonstra medo. "Sobretudo no episódio que é considerado seu feito de glória: a batalha final contra o Hermógenes." (BOLLE, 2004, p. 217)

[A] guerra descambava, fora do meu poder... [...] [E]scutava essas vozes: - Tu não vai lá, tu é doido? Não adianta... [...] e tu não tem mais nada com isso [...] Assim ouvi, sussurro muito suave, vozinha mentindo de muito amiga minha. O meu medo? Não. Ah, não. Mas meus pêlos crescendo em todo o corpo. Mas essa horrorizância. (ROSA, 2015, p. 470)

Hermógenes seria para Riobaldo uma encarnação do Mal e, durante todo o livro, ele demonstra horror de sua figura. Tentara fazer o pacto com o diabo - na verdade o episódio nos parece mais um teste para sua coragem - justamente para enfrentá-lo. Neste momento, Bolle (2004, p. 217) chama a atenção para a quantidade de vezes que Riobaldo nega ter medo (o que o acaba afirmando). Vejamos agora como aparece sua ideia da coragem nessa hora:

E ali era para se confirmar coragem contra coragem, à rasga de se destruir a toda munição. Dessa guisa enrolada: como que lavrar uma guerra de dentro e outra de fora, cada um cercado e cercando. [...] Duvidei não. Nasci para ser. Esbarrando aquele momento, era eu, sobre vez, por todos, eu enorme, que era, o que mais alto se realçava. E conheci: oficio de destino meu, real, era o de não ter medo. (ROSA, 2015, p. 478)

Bolle (2004, p. 218-219) chama à atenção de como Riobaldo realiza uma verdadeira investigação, pelo medium do romance, sobre o medo, a coragem - " $[\mathrm{Eu}]$ queria entender do medo e da coragem [...] (ROSA, 2015, p. 79) - e, mais importante e relacionado aos dois, o amor. Sendo valor fundamental para o sertanejo, a coragem, no entanto, para ele, é "variável" (ROSA, 2015, p. 38). "A verdadeira coragem é um sentimento dialético, que nasce no meio da luta" (BOLLE, 2004, p. 230). E, em meio a essa, há que se vencer o medo. De acordo com filósofos como Platão e Kant, a coragem só vale quando associada a coisas como sabedoria, justiça e amor. A origem e o sentido correto da coragem de Riobaldo vêm de sua mãe: 
"A bondade especial de minha mãe tinha sido a de amor constando com a justiça, que eu menino precisava. E a de, mesmo no punir meus demaseios, querer-me bem às minhas alegrias." (ROSA, 2015, p. 34) Diadorim the diz para recordar de sua mãe em momentos de desânimo.

Na ocasião do enfrentamento final, a coragem parece estar pervertida por estar a serviço da busca da glória pessoal, diferentemente da coragem sublime, elevada. Depois que tentou fazer o pacto com o Diabo - parece que, de certa forma, conseguiu - e se tornou chefe, Riobaldo transformouse, passando a fazer medo nos outros, e "estripolias". Essa "coragem" que Riobaldo assumira não seria a verdadeira coragem. E sua relação com Diadorim turvou-se. Ela percebeu suas mudanças e advertiu-lhe, cumprindo seu papel de "mentora" em bravura. O rompimento com Diadorim e o pacto com o Diabo são fontes de culpa para Riobaldo, ambos poderiam ser a causa da perversão de sua coragem e da tragédia da morte do amado.

$\mathrm{Na}$ segunda vez em que Riobaldo e Diadorim cruzam o São Francisco juntos, acontece o seguinte diálogo: - "Você tem receio, Riobaldo? (...) - 'Vau do mundo é a coragem..."'. (ROSA, 2015, p. 253) Aqui está o método da travessia no qual Riobaldo, àquela altura, já estava iniciado. Diadorim, como uma amante zelosa, parece querer conduzir Riobaldo pelo caminho que considera o mais digno, e que exige muita coragem - é ela que o insta a se tornar chefe, por exemplo.

Riobaldo demonstra coragem ao desafiar Zé Bebelo, que é, para ele, "o do duro - sete punhais de sete aços" (ROSA, 2015, p. 101), e que enfrenta os jagunços de Joca Ramiro com um punhal, e, depois, desarmado, no "julgamento". Ele consegue superar, de certa forma, o seu grande medo de Zé Bebelo, no momento que percebe sua intenção de traição. Vejamos como se dá a disputa entre o medo e a coragem, dentro de Riobaldo, com relação a Zé Bebelo:

Eu sendo água, me bebeu; eu sendo capim, me pisou; e me ressoprou, eu sendo cinza. Ah, não! Então, eu estava ali, em chão, em a-cú atôo de acuado?! Um ror de meu sangue me esquentou as caras, o redor dos ouvidos, cachoeira, que cantava pancada. (ROSA, 2015, p. 275-276)

Aqui vemos um medo aterrador de Riobaldo, e como o medo the causava um efeito de tensão sanguínea, que exigia uma atitude. 
Eu apertei o pé na alpercata, espremi as tábuas do assoalho. Desconheci antes e depois - uma decisão firme me transtornava. $[\mathrm{N}] \mathrm{a}$ hora de os soldados sobrechegarem, eu parava perto de Zé Bebelo; e que, ele fizesse feição de trair, eu abocava nele o rifle, efetuava. [...] Aquilo por amor do rijo leal eu fazia, era capaz; pelo certo que a vida deve de ser. [...] E eu mesmo senti, a verdade duma coisa, forte, com a alegria que me supriu: - eu era Riobaldo, Riobaldo, Riobaldo! A quase que gritei aquele este nome, meu coração alto gritou. [...] O que regeu em mim foi uma coragem precisada, um desprezo de dizer; o que disse: - "O senhor, chefe, o senhor é amigo dos soldados do Governo...” (ROSA, 2015, p. 276)

Nesse trecho, vemos como Riobaldo determina decididamente para si mesmo que enfrentaria Zé Bebelo, com uma ação simbólica física (apertar o pé), e com um plano simples e fatal. Nesse momento, a coragem está vinculada à lealdade e à justiça. Vemos, ainda, o orgulho e a satisfação que Riobaldo sente com sua coragem, que se mostra como um dever moral. É aí, então, que ele começa a desafiar Zé Bebelo. Vejamos o segundo momento de enfrentamento:

- “[...] Vou com o senhor, [...] Aí, na hora horinha, estou junto perto, para ver. [...] O que será vai ser ou vai não ser..." - alastrei, no mau falar, no gaguejável. [...] Só porque ele me mirou, ainda mais mor, arrepentinamente, e eu a meio me estarreci - apeado, goro. Apatetado? Nem não sei. Tive medo não. Só que abaixaram meus excessos de coragem [...] Todo fiquei outra vez normal demais; o que eu não queria. [...] Tive moleza, melindre. [...] Zé Bebelo luziu, ele foi de rajada: - "Ao silêncio, Riobaldo Tatarana! Eh, eu sou o Chefe!?...” [L]á como se diz - no vertiginosamente: avistei meus perigos. [...] Aí como as pernas queriam estremecer para amolecer. Aí eu não me formava pessoa para enfrentar a chefia de Zé Bebelo? (ROSA, 2015, p. 288-289)

Riobaldo ameaça Zé Bebelo, anunciando que estaria vigiando seu comportamento. Mas ele o faz com a marca da fraqueza e do medo, por gaguejar. Diante do olhar do chefe, o protagonista fica intimidado. Vemos então algumas nuances entre a coragem e o medo, e a dúvida sobre o possível estado ridículo. Aí então Zé Bebelo aproveita o medo de Riobaldo para "colocá-lo em seu lugar". Riobaldo sente medo, e questiona se poderia ou não enfrentá-lo. Imediatamente, porém, se determina a ter coragem, livrando-se do efeito intimidador do olhar de Zé Bebelo: 
Ah? Mas, aí, nem sei, eu não estava mais aceitando os olhos de Zé Bebelo me olhar. "No mundo não tem Zé Bebelo nenhum... [...] Tem esse chefe nenhum... [...]" - eu estabeleci, em mansas idéias. [A] garrei de olhar só para um lugarzinho, naquele peito [...] - aonde se podia cravar certeira bala de arma, na veia grossa do coração... [...] Teso olhei, tão docemente. Sentei em cima de um morro de grandes calmas? Eu estava estando. [D] epois ouvi minha voz, que falando a dável resposta: - "Pois é, Chefe. E eu sou nada, não sou nada [...] Sou a coisinha nenhuma, o senhor sabe? [O] menorzinho de todos. O senhor sabe? De nada. De nada... De nada..." Ao dito, falei; por quê? Mas Zé Bebelo me ouviu, inteiramente. As surpresas. Ele expôs uma desconfiança perturbada. Esticou o beiço. Bateu três vezes com a cabeça. (ROSA, 2015, p. 289)

Podemos notar que Riobaldo se impõe, primeiramente, questionando, dentro de si, a própria pessoa de Zé Bebelo, que ele tanto admirara, mas que agora parecia estar traindo seu grupo. Parece o homem de Schiller que, preparado pelo convívio com o sublime, quando diante de uma ameaça real, lida com ela como se fosse ficção, e, nesse processo, experimenta novamente a sublimidade. Em seguida, Riobaldo lembra-se de que Zé Bebelo é perfeitamente mortal. Finalmente, parece experimentar uma coragem sublime, e, a partir dessa, sua voz sai espontaneamente, desafiando o chefe com a ironia, e demonstrando que teria coragem para enfrentá-lo fisicamente.

\section{Conclusões}

Torna-se evidente que a coragem de Riobaldo se mostra e é conquistada na luta, com investidas insistentes contra a resistência do medo, e não é dada, como nos "heróis" de Euclides. A narrativa de Rosa é considerada por Bolle mais científica do que a de Euclides, especialmente na investigação da coragem e do medo, porque nela está mais presente a dúvida e a auto-reflexão. É importante frisar que Rosa mostra vários matizes entre o medo e a coragem, como exemplifica tão bem esse episódio com Zé Bebelo, que carrega ainda o valor simbólico de uma referência paterna para Riobaldo. Vemos como Riobaldo parte do medo, passa por sentimentos e estágios variados na luta com este, e adota medidas psicológicas e discursivas astutas - de acordo com suas possibilidades - para alcançar a coragem. 
Assim, sua visão é dialética e, paradoxalmente, sublime, por representar uma luta e uma coragem verossímeis. Schiller considera sublime a atitude daquele que reconhece a grandeza nas coisas existentes. Os sertanejos do Brasil são mais próximos do Grande Sertão do que d'Os Sertões. Apesar de essa obra visar claramente a sublimidade, suas concepções e metáforas para o homem do sertão são absurdas, como as que Longino ridiculariza no seu tratado.

No confronto final com o Hermógenes e os "judas", Riobaldo também se esforça para vencer o medo, mas a coragem, aqui, parece estar contaminada. A corrupção de Riobaldo pelo pacto e pelo poder acontece junto com a perda da conexão com Diadorim. E é aí que ele perde a coragem verdadeira, baseada no "amor constando com a justiça", e até fica covarde e medroso. Assim, Diadorim se confirma - desta vez, negativamente - como a figura central na formação de Riobaldo.

Os maiores medos de Riobaldo eram, na verdade, o Diabo e Diadorim - o medo de perdê-lo e o medo de amá-lo. Ambos estão relacionados: Freud (apud NASCIMENTO, 2000) associava a figura do diabo à vida instintual reprimida do inconsciente. Talvez o amor por Diadorim seja até mais uma razão secreta para Riobaldo ter buscado o pacto. Se Riobaldo falhou por ter se corrompido ao final de sua história na jagunçagem, por ter perdido a conexão íntima com Diadorim, pelo "pacto" com o Diabo e por ambição, ele também desafiou o diabo e teve um caso de amor valente com Diadorim.

A representação da coragem quase absoluta em Diadorim, bem como sua sublimidade, associadas ao disfarce do seu sexo, embora pareçam contradizer o aspecto realista do Grande Sertão que apontamos, tem uma função preponderante. É a reflexão de que realização plena só pode se dar pelo sublime, e que esse caminho, geralmente, está encoberto por aparências enganosas, e desprezado pelo receio das opiniões alheias.

Ao final, Riobaldo consegue se recuperar, e encontra conforto ao lado de Otacília. Nesse processo, a aceitação de seu destino é fundamental. Trata-se de mais um privilégio de um caráter sublime, segundo Schiller. Procuramos elucidar um pouco o ganho enorme da Literatura Brasileira quanto ao tema épico da coragem que o Grande Sertão: Veredas representa. Finalmente, é mister afirmar que os seres humanos, ganharam, com este estudo pelo medium do romance, pistas vivas dos caminhos tortuosos, mas possíveis, para se ter a coragem de enfrentar desafios e fazer a travessia da vida e da História. 


\section{Referências}

BENJAMIN, W. O narrador. In: . Magia e Técnica, arte e política: ensaios sobre literatura e história da cultura. Tradução de Sergio Paulo Rouanet. 7. ed. São Paulo: Brasiliense, 1994. p. 197-221.

BENJAMIN, W. O Surrealismo. In: . Magia e Técnica, arte e política: ensaios sobre literatura e história da cultura. Tradução de Sergio Paulo Rouanet. 7. ed. São Paulo: Brasiliense, 1994. p. 21-35.

BENJAMIN, W. Sobre o conceito da História. In: . Magia e Técnica, arte e política: ensaios sobre literatura e história da cultura. Tradução de Sergio Paulo Rouanet. 7. ed. São Paulo: Brasiliense, 1994., p. 222-243.

BOLLE, W. grandesertão.br: o romance de formação do Brasil. São Paulo: Duas Cidades; Ed. 34, 2004.

BURKE, E. Uma investigação filosófica sobre a origem de nossas idéias do sublime e do belo. Tradução de Dobránszky, Enid Abreu. Campinas, SP: Papirus: Editora da Universidade de Campinas, 1993.

DANIEL, M. L. João Guimarães Rosa: travessia literária. Rio de Janeiro: Livraria José Olympio Editora, 1968.

FIGUEIREDO, V. O sublime explicado às crianças. Transformação. Revista de Filosofia da UNESP, Marília, v. 34, p. 35-56, 2011.

FREUD, S. Novas Conferências Introdutórias à Psicanálise. In: O mal-estar na civilização, novas conferências introdutórias à psicanálise e outros textos (1930-1936). Tradução de Paulo César de Souza. São Paulo: Companhia das Letras, 2010.

KANT, I. Crítica da Faculdade do Juízo. Tradução de Valério Rohden e Antonio Marques. Rio de Janeiro: Forense Universitária, 1993.

LONGINO, Do Sublime. Tradução de Filomena Hirata. São Paulo: Martins Fontes, 1996.

NASCIMENTO, Z. A. Diadorim, uma estranha revelação: o feminino no Grande Sertão: Veredas. João Pessoa: Idéia, 2000.

ROSA, J. G. Grande sertão: veredas. 21. ed. Rio de Janeiro: Nova Fronteira, 2015. 
SCHILLER, F. Do sublime ao trágico. Organização de Pedro Süssekind, Tradução e ensaios de Pedro Süssekind e Vladimir Vieira. Belo Horizonte: Autêntica Editora, 2016.

WINE, N. Pulsão e Inconsciente: a sublimação e o advento do sujeito. Rio de Janeiro: Jorge Zahar Ed., 1992.

Recebido em: 12 de outubro de 2018 Aprovado em: 22 de novembro de 2018 